Universidad de Lima

Facultad de Comunicación

Carrera de Comunicación

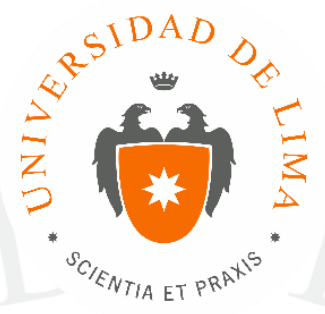

\title{
CAMPAÑA DE LANZAMIENTO CERVEZA ALBERICH ALCOHOL FREE
}

Trabajo de Suficiencia Profesional para optar el Título Profesional de Licenciado en Comunicación

Pablo Solano Uribe

Código 20131283

Lima - Perú

Setiembre de 2018 


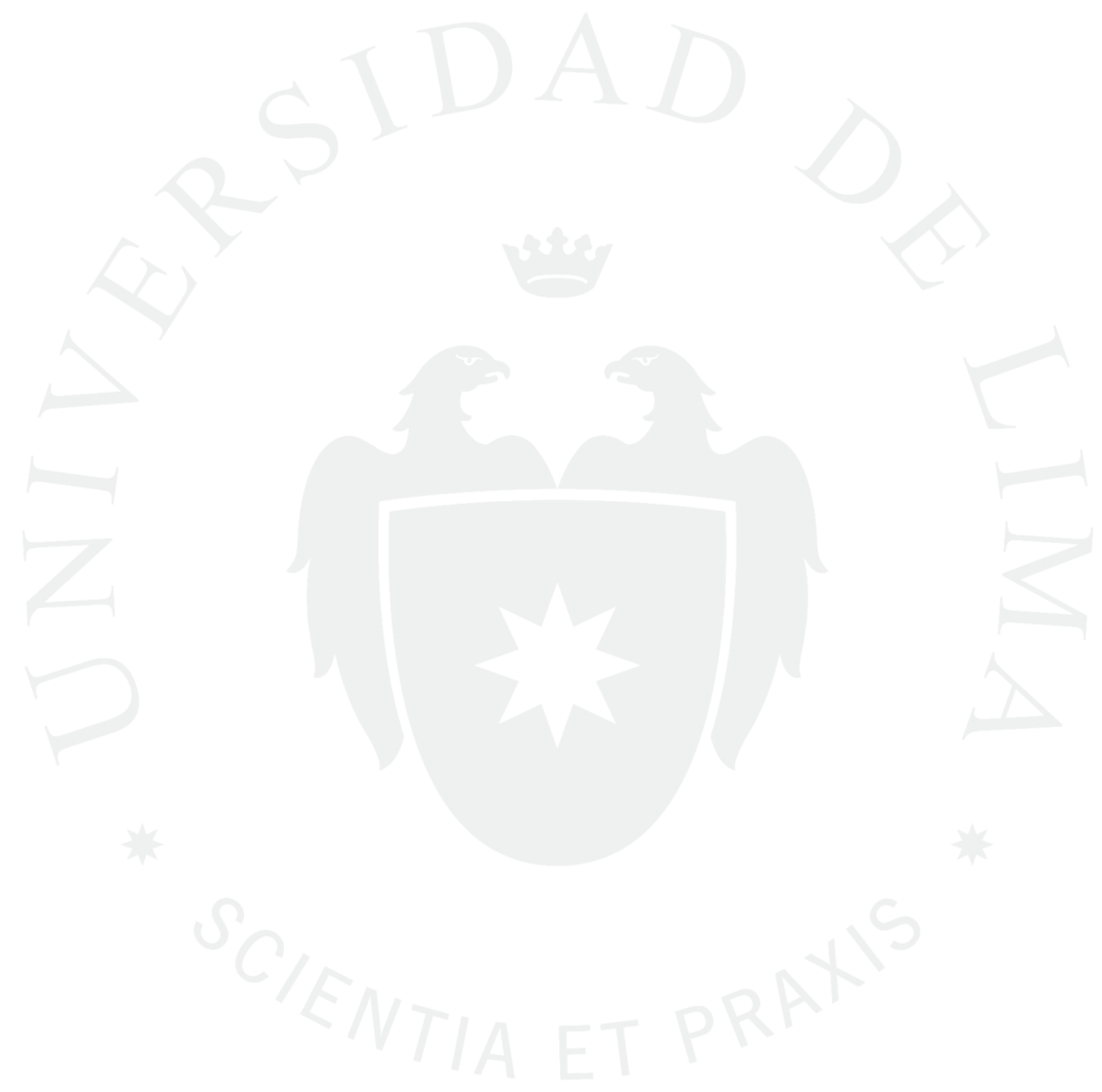




\section{CAMPAÑA DE LANZAMIENTO CERVEZA ALBERICH ALCOHOL FREE}




\section{ÍNDICE}

1.1 Mercado de bebidas alcohólicas. pág. 7

1.2 Mercado de cerveza pág. 7

1.3 Competencia pág. 8

1.3.1 Bebidas alcohólicas pág. 8

1.3.2 Bebidas sin alcohol pág. 10

2. LA EMPRESA pág. 10

2.1 Historia pág. 10

2.2 Situación actual pág. 11

2.2.1 Visión y misión pág. 11

2.2.2 Principios pág. 11

\section{HALLAZGOS CLAVE} pág. 11

3.1 Hallazgos sobre la categoría de cerveza pág. 12

3.2 Hallazgos sobre el consumidor pág. 13

3.3 Hallazgos sobre las comunicaciones pág. 15

4. LA MARCA ALBERICH ALCOHOL FREE pág. 16

4.1 Alberich Alcohol Free. pág. 16

4.1.1 ¿Por qué Alberich? pág. 16

4.1.2 ¿Por qué el duende? pág. 17

4.1.3 Justificación del nombre de marca pág. 18

4.2 Posicionamiento pág. 19

4.2.1 Storytelling pág. 19

4.3 El producto pág. 20

4.3.1 Diseño del empaque pág. 20

4.4 Público objetivo pág. 21

4.4.1 Público objetivo primario pág. 22 
4.4.2 Público objetivo secundario ................................ pág. 22

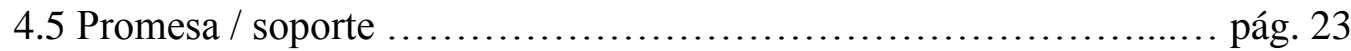

4.6 Valores y personalidad de la marca ............................... pág. 23

4.7 Concepto estratégico ...................................... pág. 23

5. CAMPAÑA DE LANZAMIENTO .................................. pág. 24

5.1 Objetivos de campaña de lanzamiento ........................... pág. 24

5.2 Plan de comunicaciones ...................................... pág. 24

5.2.1 Campaña de intriga ............................................ pág. 25

5.2.2 Campaña de lanzamiento ..................................... pág. 27

5.2.3 Campaña de mantenimiento ................................. pág. 36

5.3 Cronograma ................................................. pág. 37

5.4 Presupuesto ................................................. pág. 38

\section{REFERENCIAS}




\section{RESUMEN}

La empresa trasnacional española - alemana Sonneco incursionará por primera vez en el mercado peruano con una cerveza $0 \%$ alcohol de tipo lager y con dos presentaciones, botella de vidrio y lata de aluminio; no obstante, dado que la regulación peruana es distinta a la española, no podrán traer la fórmula clásica de la X Cero por lo que necesitarán de un nuevo producto, con un nuevo posicionamiento y un nuevo nombre de marca que le diga a los peruanos que la cerveza sin alcohol es rica y que con ella podrán divertirse y al mismo tiempo ser responsables. El presente trabajo desarrolla la propuesta de marca Alberich Alcohol Free y la campaña de lanzamiento para los primeros 6 meses.

PALABRAS CLAVE: cerveza sin alcohol, cerveza, lager, lima, Perú 


\section{ANÁLISIS DEL SECTOR}

\subsection{Mercado de bebidas alcohólicas}

El Perú es una país con una cultura de celebración en donde las bebidas alcohólicas juegan un papel muy importante. De ahí que tengamos una industria capaz de ofertar una amplia variedad de alternativas, tanto en categorías como en sabores.

A mayo del 2018 el Niño Costero había afectado negativamente la industria; no obstante, tras la clasificación al mundial de fútbol se dio un fenómeno denominado "la fiebre mundialista", durante el cual, a pesar del aumento en el impuesto selectivo al consumo (ISC), se dio un incremento del $5 \%$ en el consumo de bebidas alcohólicas, incluyendo las cervezas.

De acuerdo a Javier de la Viuda, presidente del Gremio de Vino y Licores de la Cámara de Comercio de Lima (CCL), “el consumo per cápita [de bebidas alcohólicas] es de 22 tragos al mes, cifra inferior a la de México (30), Chile (37) Argentina (42) y EE.UU. (49)" (Viuda, 2018). De los 22 tipos de bebidas alcohólicas que consume el peruano promedio, la cerveza es la de mayor preferencia, seguido por los licores y el vino (Economista, 2018).

\subsection{Mercado de cerveza}

Tras la compra de SAPMiller por parte de Anheuser Bush InBev en octubre del 2016, la empresa Unión de Cervecerías Peruanas Backus y Johnston S.A.A. consolidó dominio en el mercado de cervezas peruano con un $99 \%$ de participación, dejando el $1 \%$ restante al mercado artesanal según The Top 10.000 Companies 2017.

Si bien Backus y Johnston cuenta con un amplio portafolio de productos, su principal fuente de ingresos es la venta de cerveza. De acuerdo a una publicación del diario El Comercio, "de los S/3.965,4 millones que reportó en ventas durante el 2016, la categoría de cerveza sumó S/3.595 millones (El Comercio, 2017).

Con 5 plantas de producción de cerveza a lo largo del país (Lima, Arequipa, Cusco, Motupe y Pucallpa), la compañía es dueña de marcas emblemáticas para los peruanos como Cristal (líder en el mercado), Pilsen Callao y Cusqueña; además de otras como 
Corona, Budweiser y Stella Artois; incorporadas a partir de la fusión de SAP Miller con AB InBev.

Respecto a los distintos tipos de cervezas podemos destacar las de tipo lager, Ale, de Trigo, Porter \& Stout, Lambic, Artesanal, 0\% alcohol, entre otras. La más consumida por los peruanos es la lager. En palabras del maestro cervecero Carlos Matos, "es la que más gusta en el mundo. Son cervezas suaves, frescas, sin mucha carga alcohólica, fáciles de beber" (Matos, 2014). Dentro de esta tipología, la preferida es la cerveza cristal.

\subsection{Competencia}

La cerveza en el Perú cuenta con una larga historia que se remonta a la época colonial. Esta industria se ha desarrollado con éxito a lo largo de los años a través de varias empresas que se fundaron, crecieron, fusionaron y dividieron. Hoy, Backus y Johnston S.A.A cuenta con las principales marcas de cerveza en el mercado peruano; no obstante, aún no ha incursionado en la subcategoría de cerveza sin alcohol.

\subsubsection{Bebidas alcohólicas}

Cristal es la cerveza líder del mercado peruano y la de mayor preferencia a nivel nacional. Con un color dorado y un fresco sabor con el amargo justo, la marca se ha convertido en "Orgullosa Embajadora de la Marca Perú", uniéndonos como peruanos y siendo parte de toda nuestras celebraciones. Actualmente ha construido su posicionamiento entorno al concepto de "barrio", el cual no se refiere solo al espacio físico sino al espíritu de vivir en un barrio.

Pilsen Callao es otra de las cervezas de tipo lager más consumidas dentro del mercado y es además la más antigua del Perú. Con un balance perfecto de lúpulos y un sabor simple, confiable y aromático, la cerveza se ha mantenido en los más altos niveles de preferencia en el mercado, cumpliendo con un solo propósito, reunir a los amigos de verdad. De ahí que su slogan sea "Pilsen Callao es el sabor de la verdadera amistad".

La Cusqueña lager es otra de las cervezas más apreciadas del Perú debido a su proceso único de elaboración y a su exquisito sabor, el cual se consigue utilizando $100 \%$ malta de cebadas seleccionadas en combinación con el más fino lúpulo aromático. Esta cerveza resalta toda la tradición de la cultura peruana, su etiqueta está 
inspirada en nuestra maravilla del mundo Machu Pichu, la botella presenta a la famosa piedra de los doce ángulos ubicada en el departamento de Cusco, y sus colores, el dorado, remiten al incanato y al Dios Sol. De este modo Cusqueña se construye en base al orgullo de ser peruanos.

Dentro de la tipología lager, Backus también cuenta con otras marcas globales como Corona, Budweiser y Stella Artois. La primera se presenta como la líder del mercado en este nicho, con crecimientos anuales de doble dígito. En palabras de José Luis Eyzaguirre, director de Marcas Globales en Backus AB InBev, "el éxito que ha tenido Corona en el Perú es producto de su diferenciación. Desde su diseño (vidrio transparente con etiqueta grabada), el ritual de tomarla con limón hasta el concepto de relax, han hecho que el consumidor sienta que esta es una marca aspiracional al alcance de la mano (Eyzaguirre, 2017). Dicho beneficio de autoexpresión se ve reforzado por el concepto detrás de la marca, coger una corona y convertirse en rey.

Budweiser es una de las marcas cerveceras más famosas e icónicas del mundo, la cual llegó al Perú en el año 2014 como parte de la estrategia de AB InBev para expandir su portafolio de productos. Si bien la marca ya contaba con un posicionamiento fuerte a nivel global, fue recién con la clasificación de la selección peruana al mundial de fútbol con que se abrió espacio en el mercado cervecero peruano. De este modo construyó su posicionamiento como "la cerveza oficial de Rusia 2018" e implícitamente como "la cerveza oficial de la vuelta de la selección peruana a un mundial después de 36 años”.

Finalmente la Stella Artois es una sofisticada lager de origen europeo con más de 600 años de tradición cervecera. Se caracteriza por un sutil amargo que la convierte en el complemento perfecto de diversos platos. Su más reciente campaña se desarrolló bajo el concepto "Joie de Bière", el cual proviene del francés "Joie de Vivre" que significa alegría de vivir. De este modo la marca deja de lado su tradicional slogan "razonablemente cara" para volcarse en uno en donde se motive a los consumidores a aprovechar la vida.

\subsubsection{Bebidas sin alcohol}

Respecto a la competencia dentro de la tipología sin alcohol, también conocida como alkoholfrei, se destaca la cerveza Erdinger - Alkohol Free y Bitburger Drive. Esta última tiene un contenido alcohólico de tan solo $0,1 \%$ y se caracteriza por respetar los estilos visuales de la tradicional lager, color pajizo de buena claridad y una generosa 
cabeza de espuma blanco tiza. Por otro lado, la Erdinger - Alkohol Free contiene 0,5\% de alcohol por volumen y es una cerveza de trigo. Visualmente mantiene la apariencia de un cerveza corriente; no obstante, y en palabras del "Gourmetógrafo", "su sabor recuerda ligeramente al pequeño maíz dulce en mazorca de los estadounidenses y su cuerpo es ligero medio" (Gourmetógrafo, 2016).

\section{LA EMPRESA}

Sonneco es una empresa española - alemana dedicada a la producción y comercialización de bebidas de consumo masivo. Su objetivo principal es ofrecer productos con la más alta calidad que contribuyan al bienestar del ser humano y al desarrollo sostenible.

\subsection{Historia}

El señor Pedro Valdivia funda Sonneco en 1950 como un negocio familiar dedicado a la comercialización de bebidas gaseosas. En el año 1975 el negocio se expande y comienza a producir bebidas alcohólicas de tipo lager con un bajo nivel de alcohol. Ante el éxito en ventas, en el año 1976 lanza al mercado la famosa cerveza de trigo X CERO, con un $0,05 \%$ de alcohol. A partir de ahí Sonneco decide integrar verticalmente el negocio y empieza a comercializar la bebida a distintos mercados, ganando posicionamiento como una de las principales marcas de cerveza sin alcohol.

Actualmente la empresa pretende hacer su entrada al mercado sudamericano, incluyendo el Perú, país con una tradición cervecera que resulta atractiva para Sonneco. No obstante, dado que la reglamentación peruana especifica que si la cerveza no contiene $0,0 \%$ de alcohol no se puede comercializar como cerveza "sin alcohol", a diferencia de España en donde basta con tener menos de 1,2 grados para ser considerada "no alcohólica", Sonneco ha decidido lanzar una nueva marca de cerveza lager con $0,0 \%$ de alcohol, exclusiva para los paladares más exigentes y responsables del mercado peruano. 


\subsection{Situación actual}

\subsubsection{Visión y misión}

Misión: "Nuestra misión es contribuir al bienestar de la comunidad suministrando bebidas con bajo o nulo grado de alcohol en el mercado global”.

Visión: "Nuestra visión es ser líderes en la subcategoría de cerveza sin alcohol a nivel mundial, suministrando productos de calidad y nutritivos para el ser humano".

\subsubsection{Principios}

La empresa se rige por los siguientes principios:

- Salud y Bienestar: "Buscamos mejorar la calidad de vida de los consumidores en cada momento y en todo lugar".

- Relaciones con proveedores y clientes: "Estamos comprometidos con nuestros proveedores y clientes para mantener honestidad, justicia y respeto de las normas".

- Sostenibilidad medioambiental: "Contamos con prácticas empresariales medioambientalmente sostenibles".

- Innovación: "Buscamos la excelencia como estándar y la mejora continua de nuestros procesos para así entregar el mejor producto posible".

\section{HALLAZGOS CLAVE}

La empresa Sonneco había conseguido establecer vínculos emocionales con sus clientes al ser de las primeras en comercializar una bebida con bajo grado de alcohol, algo especialmente atractivo para un consumidor cada vez más responsable y consciente de la falta que implica manejar en estado de ebriedad. A esto se le suma la nueva tendencia a un estilo de vida más saludable que hay entre los jóvenes y el prejuicio de que la cerveza con alcohol saca barriga. 


\subsection{Hallazgos sobre la categoría de cerveza}

La cerveza es el trago más consumido del Perú en los sectores B, C y D que son justo donde hay más habitantes. De ahí que de acuerdo a un reciente estudio en Latinoamérica, el Perú se encuentre entre los cinco países con mayor consumo de cerveza per cápita de la región, con un indicador de 45.4 litros por persona al año (Euromonitor, 2016).

Otro hallazgo es el impacto que ha tenido el crecimiento económico en el consumo de los peruanos, el cual ha permitido el ingreso de nuevos productos y diversos estándares de calidad. A esto se le suma la rápida expansión de los supermercados, permitiendo ofrecer productos diferenciados de acuerdo al nivel de ingreso del consumidor, llevando esta facilidad a diversas ciudades del país, además de tener poder de negociación directa con el fabricante y así poder ofrecer mayores descuentos para promover el consumo. Como parte de este crecimiento se ha dado un aumento en la importación de productos, incluidos la cerveza.

TABLA 1. Evolución importaciones de cerveza enero - agosto (2012 - 2016)

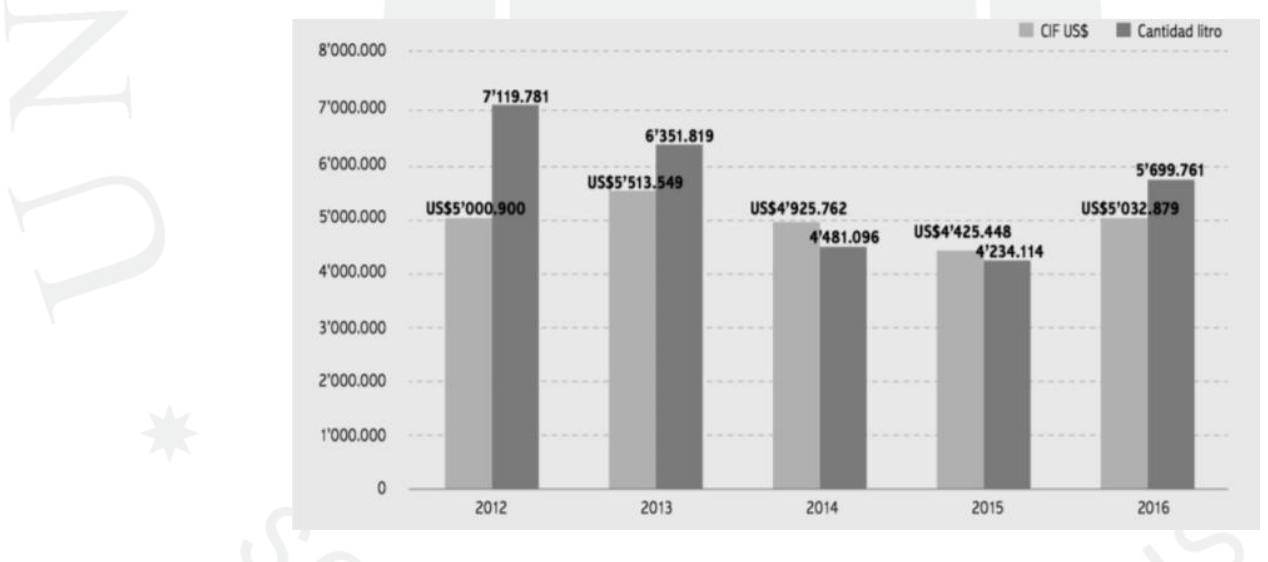

Fuente: CAMTRADE

Tal como se puede ver en el gráfico, durante el periodo del 2014 al 2015 se dio un descenso en las importaciones de cervezas de litro; no obstante, para el 2016 se observa una variación positiva del $35 \%$ respecto al año anterior, esto como consecuencia de la recuperación económica.

Finalmente tenemos la tendencia a la "premiumización", entendida como la preferencia cada vez mayor por cervezas Premium ya sean tradicionales como artesanales, ambas de precio superior al promedio. De este fenómeno se explica el 
creciente interés de los peruanos por cervezas importadas, siendo la más consumida la Corona, y las cervezas artesanales; no obstante, el número de litros importados de esta última aún es poco representativo respecto a la cerveza convencional.

\subsection{Hallazgos sobre el consumidor}

Cuando Sonneco decide ingresar al mercado peruano se da cuenta de algo, el consumidor es fiel a sus marcas más tradicionales (Cristal, Pilsen Callao y Cusqueña). Para los peruanos, la cerveza es mucho más que una simple bebida de celebración o de eventos sociales. En los cerca de 150 años que tiene el consumo de cerveza industrial en el Perú, esta se ha convertido en un objeto nostálgico para muchos, de ahí que apreciemos más que nadie sus sabores, el amargo de su fermentación, la temperatura ideal, entre otros. No obstante, existe un público tanto joven como adulto que gusta probar nuevas marcas y sobre todo nuevos productos. De ahí el éxito reciente de las cervezas artesanales. Tal como señala Alain Schneider, principal responsable en la organización del Lima Beer Week, “a comparación del año pasado, se pasó de 600 mil litros anuales [de cerveza artesanal] a un millón al concluir el 2017” (Schneider, 2017).

Respecto al segmento de cervezas sin alcohol, un hallazgo clave es el prejuicio que tienen los peruanos respecto a esta bebida: se le considera mayormente como una bebida cara y sin sabor.

Del mismo modo los peruanos sienten una mayor confianza por aquellas cervezas que recalcan el carácter Premium o exclusivo de su producto, dándoles una razón extra que justifica la compra. Este carácter exclusivo o superior también se ve reflejado por el país de origen de la cerveza. Es decir, si uno pasea por las góndolas de un supermercado y quiere probar una cerveza distinta y superior a las ya conocidas del mercado peruano, es muy probable que elija las de procedencia alemana, belga, holandesa, entre otras. Esto muchas veces se ve evidenciado en el nombre de la cerveza. Otro descubrimiento importante es el rol que puede tener la etiqueta a la hora de elegir una cerveza. En circunstancias en donde se desconoce la calidad de las marcas, los peruanos tienden a prestarle mayor interés a los productos que se destacan del resto, los que llaman la atención desde la góndola.

La cerveza además tiene un uso social al que vale la pena prestarle atención. Los jóvenes entre 15 y 30 años suelen ir a reuniones / fiestas en donde cada vez resulta más importante tener una botella en la mano. En palabras de Sergio Parra, editor y 
coordinador de XatakaCiencia, "todos, salvo casos patológicos, hemos evolucionado para prosperar en grupos sociales. La soledad y la individualidad son sinónimos de muerte en el contexto evolutivo" (Parra, 2016). Esto significa que todos necesitamos encajar en algún grupo. Para los jóvenes tomar es un sinónimo implícito de estar a la moda, de verse bien, de pertenecer al grupo. Siempre los que no toman son los considerados "aburridos". También están los que no toman y se excusan diciendo que están manejando, los cuales son vistos como responsables, pero de igual modo aburridos.

En el Perú, el grado alcohólico máximo permitido a los conductores que sean intervenidos por la autoridad se establece en 0,50 gramos de alcohol por litro de sangre (D. S. Nro 016-2009-MTC, art. 307), lo que equivale a 3 vasos de cerveza o a 2 copas de vino. El conductor que sobrepase este límite puede recibir una multa del 50\% de una Unidad Impositiva Tributaria (UIT) y del 100\% si es que, estando ebrio, participó de un accidente de tránsito. De ahí que los jóvenes cada vez opten por tomar taxis en vez de manejar o prefieran simplemente no tomar.

Respecto a los hábitos, usos y actitudes hacia los medios tanto tradicionales como no tradicionales, también se han encontrado hallazgos útiles. De acuerdo a un estudio de IPSOS, los jóvenes pertenecientes al NSE A y B no suelen leer diarios, sólo el $25 \%$ lo hace. Los momentos preferidos son los días miércoles, sábados y domingos de 9:00 am a 12:00 pm (IPSOS, 2017). Así mismo, los diarios más leídos por dicho segmento son Trome con aproximadamente el $16.1 \%$ de lectoría; seguido por El Comercio con $12.2 \%$ de lectoría; y Publimetro con 3.4\% (CPI, 2017).

La televisión sigue siendo el medio más consumido por los peruanos. De acuerdo a un reciente estudio de CONCORT, se evidencia que los programas favoritos de los peruanos son los de tipo informativo, América noticias - primera edición (20\%); América noticias (20\%); Noticias: 90 (18\%); Esto es guerra (13\%); América noticias edición central (12\%); y Central de noticias ATV (10\%). Siendo los canales más vistos América televisión, Frecuencia Latina y ATV (CONCORTV, 2018).

También se han encontrado hallazgos respecto a las actitudes de los peruanos en redes sociales. De acuerdo a un reciente estudio de IPSOS, los usuarios del NSE A y B suelen conectarse de forma intensiva a internet, siendo Facebook y WhatsApp las plataformas preferidas del segmento. Además son el grupo que más sigue influencers.

Finalmente se tiene como dato clave que a la mayoría no le gusta la publicidad en Facebook, tal como señala IPSOS, dos de cada diez considera que esta es relevante. 
En Instagram la historia es diferente, ahí sí hay un porcentaje interesante que le agrada la publicidad (el 25\%), así como un porcentaje que la considera relevante (19\%). En otras palabras, es un espacio a explotar.

\subsection{Hallazgos sobre las comunicaciones}

Respecto a las comunicaciones, un hallazgo importante es el rol que ahora tienen las mujeres en el sector cervecero. Por mucho tiempo se tenía la idea de que las mujeres no tomaban cervezas o que no les gustaba, estereotipo que ahora esta cambiando. Hoy cada vez son más las marcas que vienen apostando por mujeres dentro de sus comunicaciones, en lugar de retratarlas como objetos de deseo. Si bien esto en el Perú aún se encuentra incipiente con algunos esfuerzos por parte de Pilsen Callao y Tres Cruces, representa una oportunidad estratégica importante.

Otro hallazgo clave es el tono en que las marcas de cervezas peruanas "tradicionales" se comunican con su target. Pilsen Callao apela a la nostalgia y la amistad, insight poderoso en el mercado peruano. Su comunicación gira en torno a compartir un momento entre amigos; por otro lado, Cristal apela al barrio, un término bastante conocido en la realidad peruana que alude al segmento mayoritario del país. De este modo su comunicación acerca la marca a todos los barrios del Perú, haciéndolos participes de sus eventos y actividades. Cusqueña se enfoca más en la tradición y el orgullo de ser peruanos, es la cerveza Premium del Perú. Las tres marcas, al igual que las trasnacionales, tiene un manejo de comunicación tanto por medios tradicionales como no tradicionales. En este último se aprovechan las plataformas digitales para inducir la interacción entre los consumidores y la marca, humanizándola y haciéndola "pata” de su target. Así mismo utilizan el espacio para comunicar el auspicio de eventos y así asociar a la marca con un tipo de público y un tipo de espacio. Un ejemplo de ello es Cristal, la cerveza de la selección peruana. Durante la época del mundial la marca organizó concursos para "llevar al barrio" a alentar a la selección en Rusia; así mismo una vez terminada la competición pusieron murales en las calles con frases como "el profe se queda en el barrio", en alusión a la continuidad de Gareca. En conclusión, la marca está fuertemente vinculada con la selección, en las buenas y en las malas.

De lo anterior se encuentra una oportunidad de negocio, todas las marcas aluden a la diversión y al compartir un momento agradable, pero ninguna ahonda en la problemática que viven algunos y que cada vez es más recurrente: no poder tomar 
alcohol ya sea por estar manejando, por estar medicado, por tener reunión al día siguiente, etc. No hay ninguna marca que se preocupe por esas personas ni que les proponga una solución. A fin de cuentas estamos hablando de un consumidor amante de la cerveza que por alguna circunstancia no puede o no debería tomar.

A partir de los hallazgos mencionados, Sonneco encuentra un terreno poco explorado, el de las cervezas sin alcohol, y un target desatendido que en lugar de divertirse o sentirse parte de la fiesta opta por no tomar y estar "sin hacer nada". En consecuencia, no llega a disfrutar "plenamente" la fiesta ni llega a encajar en el grupo.

\section{LA MARCA ALBERICH ALCOHOL FREE}

En el Perú, a diferencia de España, la reglamentación de protección al consumidor es más estricta. Ninguna marca de cerveza puede anunciar que es "sin alcohol" si no tiene $0.00 \%$ de alcohol. En este sentido, Sonneco no podía llevar la fórmula clásica de la X Cero y comunicarla como "sin alcohol", dado que esta marca contiene 0,05\% de alcohol. Como respuesta, optaron por el lanzamiento de una nueva cerveza para la región: Alberich Alcohol Free.

\subsection{Alberich Alcohol Free}

Es una cerveza alemana tipo lager de color amarillo dorado que contiene $0,00 \%$ de alcohol, siendo la primera en el mercado peruano con esas características (Bitburger tiene $0,1 \%$ y la Erdinger tiene menos de 0,5\%vol. Alc.). Su cuidadosa elaboración garantiza el punto exacto de equilibrio entre amargura y dulzura, logrando capturar toda la esencia de la cerveza lager alemana pero sin ningún porcentaje de alcohol.

\subsection{1 ¿Por qué Alberich?}

En el folclore alemán existen muchas tradiciones y leyendas en donde los duendes son los principales protagonistas. A partir de estudios de antropólogos y folcloristas se puede concluir que estas criaturas no son ni buenas ni malas, sino neutrales. Son fuerzas de la naturaleza a las que es posible convertir tanto en aliadas como en enemigas, dependiendo de nuestra actitud hacia ellas. 
Situándonos en la gran epopeya alemana de la Edad Media, un enano llamado Alberich juega un papel importante. El término "Alberich" se traduce como "duende soberano", término que más tarde evolucionaría a "duende enano". De acuerdo a la Real Academia Española (RAE), "soberano" se define como aquel "que ejerce o posee autoridad suprema e independiente" (RAE, 2018); alguien que es muy grande, extraordinario. Así, Alberich es ese duende soberano que nos ofrece la tradición alemana mezclada con fantasía y majestuosidad.

GRÁFICA 1. Propuesta de nombre para la marca

\section{Alberich}

Fuente: Elaboración propia

\subsection{2 ¿Por qué el duende?}

Los duendes son criaturas traviesas, sumamente astutas y llenas de magia que pueden habitar en casas o en la naturaleza. Físicamente se describen como personas de baja estatura, no mayor a un metro, con orejas, pies y nariz largas, piel verdosa, los cuales en ocasiones entran en contacto con los humanos. El término duende procede de la expresión "duen de casa" (dueño de la casa), supuestamente por la costumbre que tienen por invadir hogares. Los duendes además son algo muy presente de la cultura alemana. Un claro ejemplo de ello es la tradición de poner duendes de arcilla en los jardines para brindar protección y traer buena suerte. Dicha costumbre comenzó en el estado minero de Turingia, Alemania, en donde los artesanos esculpían y pintaban a manos estas barbudas figuras.

GRÁFICA 2. Propuesta de duende para la marca

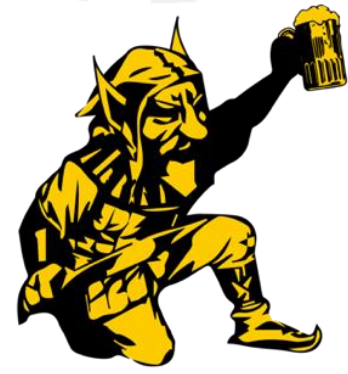

Fuente: Elaboración propia 


\subsubsection{Justificación del nombre de marca}

Sonneco requiere lanzar su nuevo producto de modo tal que se destaque su agradable sabor, su contenido $0,00 \%$ de alcohol, y sus puntos de venta.

El reto está en vencer el prejuicio que se tiene respecto al sabor de la cerveza sin alcohol; no obstante, se tiene una oportunidad en la nacionalidad del producto. Un insight clave es que los peruanos relacionan la cerveza alemana con una cerveza de calidad cuyo sabor debe ser indudablemente delicioso. Esta percepción no solo está arraigada en nuestro país sino que es latente a nivel global, de ahí que según reportes de la BBC, Alemania exporte 1.5 mil millones de litros de cerveza al año (BBC, 2016).

Para vencer este prejuicio resulta importante construir el posicionamiento de la marca en torno a su país de origen y apoyarlo con todas las herramientas de marketing pertinentes al caso. Asociar al producto con su país de origen le puede dar una mayor credibilidad al relacionarse con la tradición cervecera alemana.

Alberich es una palabra alemana corta, fácil de pronunciar y de recordar, que se encuentra disponible en la categoría de cervezas y que cuenta con un trasfondo conceptual vinculado a la tradición alemana. Así mismo, con el objetivo de ir más allá del nombre y poder conectar emocionalmente con el target, se ha desarrollado una historia detrás del duende, creando un personaje irreverente, alegre y divertido.

GRÁFICA 3. Propuesta de logo para la marca

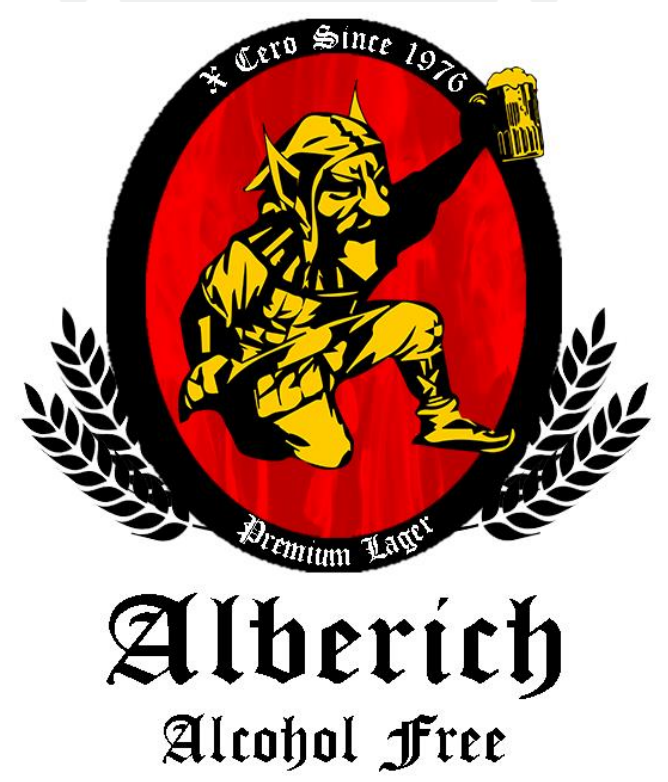

Fuente: Elaboración propia 


\subsection{Posicionamiento}

Queremos ser la primera cerveza lager con $0.00 \%$ de alcohol que mantiene el rico sabor de la cerveza alemana. Para ello resulta clave hacer énfasis en el carácter alemán de la cerveza.

El posicionamiento de la nueva cerveza se construye de forma narrativa, es decir, a través de metáforas y una historia en donde se hable de los beneficios y atributos del producto. En este caso se plantea la historia de un duende enano, Alberich, que encuentra la fórmula para tomar una cerveza lager cero alcohol sin que nadie se de cuenta.

\subsubsection{Storytelling:}

En una aldea de duendes existía la tradición de que todo los fines de semana, empezando por los jueves, eran de fiesta. Los bares reventaban y el juego de siempre era quién podía tomar más cervezas y mantenerse sobrio. Un día llegó un duende que nadie conocía y decidió retar al campeón de la aldea, causando sorpresa entre los presentes. Esa noche el duende extraño lo venció, nadie lo podía creer, la cerveza no le hacía efecto. Algunos escépticos le pidieron probar lo que estaba tomando pero todo parecía normal, era una deliciosa cerveza lager, tal como las que tomaba el resto. Alberich, nombre que recibió el duende por su soberanía en el pueblo, volvió a ganar todos los fines de semana durante varios años, pues había encontrado una fórmula de cerveza lager sin alcohol con la cual podía engañar hasta el paladar cervecero más exigente.

Siglos más tarde, Alberich se encontraba rumbo a su casa cuando vio una escena que lo marcó por el resto de su vida. Era una fiesta a las afueras de la ciudad, todos tomaban excepto uno que se encontraba sentado y aburrido. Curioso, se acercó entre los arbustos y vio que cada vez que le invitaban un trago, el extraño sujeto decía que no, pues tenía que conducir una de esas máquinas modernas llamadas automóviles. Entonces se le ocurrió una brillante idea, compartir su fórmula secreta con aquellas personas responsables amantes de la cerveza que no pueden consumir alcohol pero quieren sentirse parte de la fiesta. Después de todo, los fines de semana son de diversión y una cervecita bien helada siempre cae bien. 


\subsection{El producto}

La cerveza Alberich Alcohol Free viene en dos presentaciones, en botella de vidrio 310 $\mathrm{ml}$ y en lata de aluminio $355 \mathrm{ml}$. A continuación se presentará la propuesta de diseño de empaque para las dos versiones.

\subsubsection{Diseño del empaque}

Para la presentación en botella de vidrio se ha optado por una de color marrón oscuro con el fin de garantizar la correcta entrega del exquisito sabor que ofrece la marca.

Tomando como referencia el artículo "What Does the Color of Your Bottle Mean?” De Berghoff Beer, tenemos que si la cerveza se deja al sol de forma prolongada es muy posible que empiece a oler mal y se perjudique el sabor. Esto debido a que los rayos ultravioleta descomponen los ácidos alfa del lúpulo. El color marrón justamente ayuda a conservar la cerveza por más tiempo.

Respecto al diseño de etiqueta, se propone una de color blanco que resalte el logo de la marca. El objetivo es generar impacto visual por sobre el resto de cervezas, que cuando uno esté paseando por las góndolas se detenga y lleve una Alberich. De este modo, y tras analizar los colores de etiqueta presentes en el mercado peruano, se llegó a la conclusión de que el blanco es el color ideal. En primer lugar porque casi no hay cerveza que tenga su etiqueta en ese color. $\mathrm{Y}$ en segundo lugar por la fuerza y jale visual que le da al logo de la marca.

El logo ha sido cuidadosamente trabajado con la paleta de colores de la bandera alemana. En este sentido tenemos un escudo rodeado por cebada, dentro del cual aparece el duende Alberich cargando una cerveza en un fondo rojizo en llamas que destaca la figura del personaje. El nombre de marca también ha sido tratado de modo que resalte la tradición cultural alemana (uso de tipografía "Cloister"). La idea es que a simple vista, tanto la botella como la lata, denoten estatus, tradición cervecera, calidad y sobre todo el buen sabor de la cerveza alemana. Cabe mencionar que para el diseño del logo se optó por mencionar a "X Cero" como marca respaldadora de Alberich Alcohol Free, ya que a nivel mundial cuenta con un fuerte posicionamiento en el rubro de cerveza "sin alcohol", lo que puede darle a nuestro producto una mayor credibilidad en su propuesta de valor. 
GRÁFICA 4. Propuesta de botella para Alberich
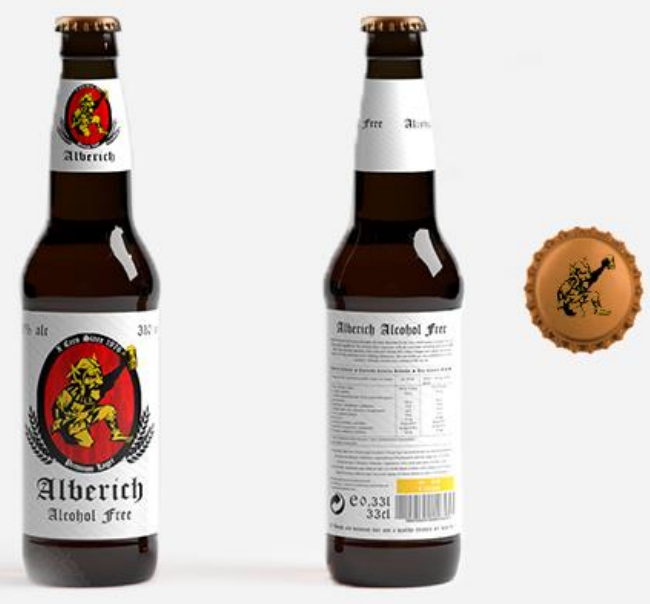

Fuente: Elaboración propia

GRÁFICA 5. Propuesta de lata para Alberich

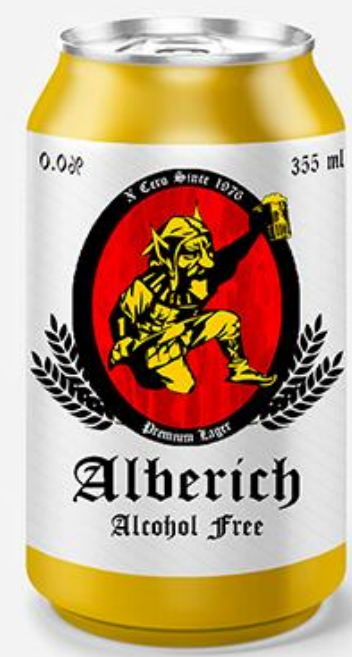

Fuente: Elaboración propia

\subsection{Público objetivo}

Para la presente campaña de lanzamiento se divide al público objetivo en uno primario y uno secundario, estando el primero conformado por jóvenes limeños de 18 a 24 años del NSE A y B, y el segundo por adultos jóvenes limeños de 25 a 39 años. 


\subsubsection{Público objetivo primario}

Conformado por jóvenes limeños entre 18 a 24 años pertenecientes a los niveles socioeconómicos (NSE) A y B, según la compañía peruana de estudios de mercados y opinión pública (CPI). Este público contempla tanto hombres como mujeres con un estilo de vida moderno y sofisticado según el estudio de Arellano Marketing. La mayor parte de ellos vive en la capital, siendo más específicos en la zona 7 (Miraflores, La Molina, San Borja, San Isidro y Surco).

Como aspectos socio y psicográfico tenemos que son estudiantes universitarios o de instituto, que tienen un estilo de vida sociable y activo. Gustan salir los fines de semana, empezando por los jueves y les preocupa su imagen personal. Son cazadores de tendencias. Si un bar está de moda, pues ese será el "point" para las salidas de fin de semana. Si una discoteca ya pasó de moda, pues buscarán aquella en donde todo el mundo esté yendo. Les interesa no desentonar con el grupo en el que se encuentran, sentirse parte de la "mancha". De ahí que los previos sean tan importantes, ya que es ahí en donde se reúnen a tomar para luego salir a bailar.

Otra característica del target es la preocupación e información que tienen respecto a su salud y los riesgos de beber alcohol y manejar. Por ello cada vez son más los jóvenes que optan por pedir taxis en lugar de manejar. Así mismo la mayoría se encuentra en una red social, siendo las más utilizadas Facebook con un 84\%, WhatsApp con un $52 \%$ e Instagram con $29 \%$ (IPSOS, 2018)

\subsubsection{Público objetivo secundario}

Conformado por adultos jóvenes entre 25 y 39 años, de los NSE A y B, pertenecientes a Lima Metropolitana; este segmento cuenta con características muy similares a las del anterior pero con algunas diferencias. En primer lugar, cuentan con un mayor poder adquisitivo producto de un trabajo más estable. Tal como señala IPSOS, siete de cada diez se encuentra trabajando, la mayoría como colaborador en alguna empresa (IPSOS, 2018). Así mismo el $33 \%$ se encuentra soltero, mientras que un $27 \%$ ya se encuentra conviviendo. Algunos incluso se han casado y tienen hijos pequeños, lo que les significa asumir nuevas responsabilidades. De acuerdo a un reciente estudio de IPSOS, 3 de cada cinco adultos jóvenes son padres y tienen en promedio 1 hijo (IPSOS, 2018). 
Si bien ya no son jóvenes, gustan salir con sus amigos y hacer reuniones en sus casas. La diferencia es que ahora tratan de cuidarse más en su consumo de alcohol, saben que las resacas ya no son las mismas. Así mismo, y con el objetivo de no ser detenidos por manejar en estado de ebriedad, la mayoría opta por viajar en taxis o pedir choferes de reemplazo. De hecho, el uso de aplicaciones es bastante recurrente en el target. Tal como se presenta en el estudio sobre redes sociales de IPSOS, 3 de cada 4 jóvenes adultos es miembro de una red social, siendo Facebook y WhatsApp las más populares, seguido de Instagram y Twitter; no obstante, a pesar de ser digitales la mayoría no compra por internet (IPSOS, 2018).

\subsection{Promesa / soporte}

Promesa: Tu cerveza lager favorita con los más altos estándares de calidad para que disfrutes sin preocupaciones.

Soporte: La cerveza lager tiene el punto medio (3 de 5) de amargura y dulzura preferido por los peruanos (Cristal tiene 3 de amargo y 2 de dulce; Pilsen 3 y 3 ; y Cusqueña 3 y 3). Además cuenta con el más exquisito sabor al tratarse de una cerveza $100 \%$ alemana. Por último, te garantiza poder disfrutar sin ningún tipo de preocupaciones ya que no contiene alcohol (0,00\% vol. Alc.), así tomes 2 litros de cerveza no vas a tener ningún problema con la policía ni con tus responsabilidades.

\subsection{Valores y personalidad de la marca}

Alberich está comprometido en contribuir a un estilo de vida más sano y responsable entre los jóvenes y adultos jóvenes, sin que ello implique dejar de divertirse o dejar de hacer aquello que a uno le gusta. Respecto a la personalidad de la marca, Alberich es una persona moderna, responsable y con un gusto exquisito que busca estar siempre a la moda, siguiendo lo último en tendencias. Es carismático, cercano y confiable, sabe lo importante que es ser responsable pero también lo importante que es divertirse y sobre todo lo rico que es compartir una cerveza lager bien helada con los amigos.

\subsection{Concepto estratégico}

El buen sabor de la diversión sin preocupación. 


\section{CAMPAÑA DE LANZAMIENTO}

\subsection{Objetivos de campaña de lanzamiento}

\section{Objetivos de marketing:}

- Generar conocimiento y recordación de marca por parte del target objetivo en el lapso de 6 meses.

- Alcanzar el liderazgo en el rubro de bebidas sin alcohol, en el mercado peruano, en el lapso de un año.

\section{Objetivos de comunicación:}

- Informar sobre el lanzamiento de Alberich, destacando su agradable sabor y que no contiene alcohol.

- Informar sobre los puntos de venta de la marca.

\subsection{Plan de comunicaciones}

Para el lanzamiento de Alberich Alcohol Free se va a dividir el plan de comunicaciones en tres etapas. Primero una campaña de intriga en redes sociales que durará dos semanas. Una vez se genere reconocimiento entre el target, se desarrollará la campaña de lanzamiento tanto en medios tradicionales como en no tradicionales, la cual tendrá una duración de 4 meses. Finalmente se llevará a cabo la etapa de mantenimiento en redes sociales. A continuación un resumen del plan integral de comunicaciones.

ESQUEMA 1. Plan de comunicaciones

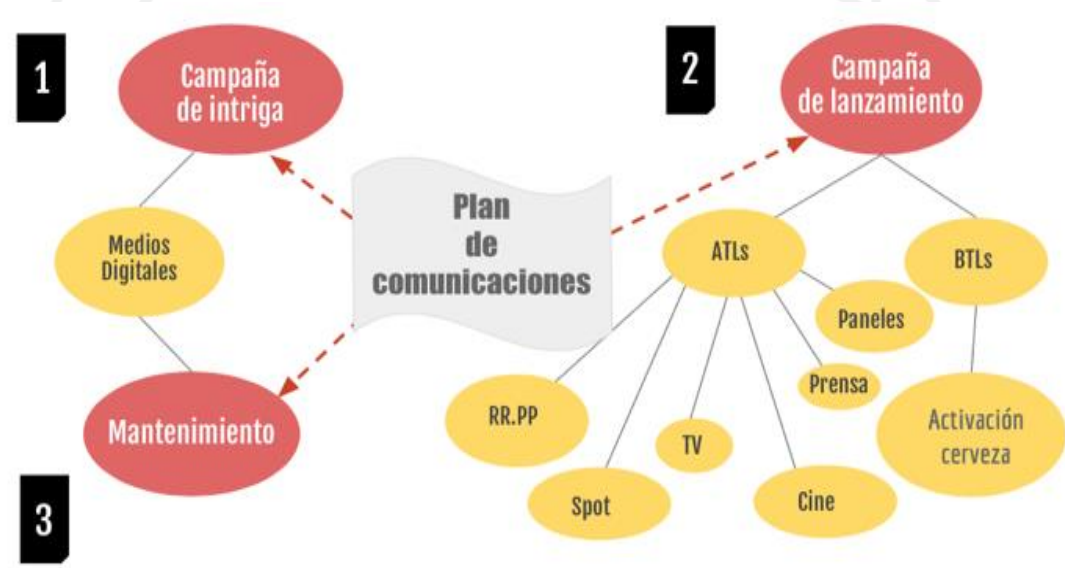

Fuente: Elaboración propia 


\subsubsection{Campaña de intriga}

La campaña de intriga se desarrollará principalmente en medios digitales teniendo como plataformas de acción Facebook e Instagram. El objetivo será primero dar a conocer la existencia de Alberich como marca asociada a la categoría de cerveza; y segundo, generar interacción entre la marca y la comunidad. Para ello se desarrollarán una serie de post irreverentes y retadores que inviten a la gente a querer saber más sobre el producto. Así mismo, dado que el target tiene simpatía por los influencers, se trabajará con ellos para que cuenten pequeñas historias graciosas sobre fiestas o "reus" en donde no pudieron "divertirse" por tener que manejar o ser el amigo elegido, etc. Esto con el fin de hacer énfasis en lo bueno que sería tener una cerveza totalmente sin alcohol.

GRÁFICA 6. Propuesta de post intriga para Alberich
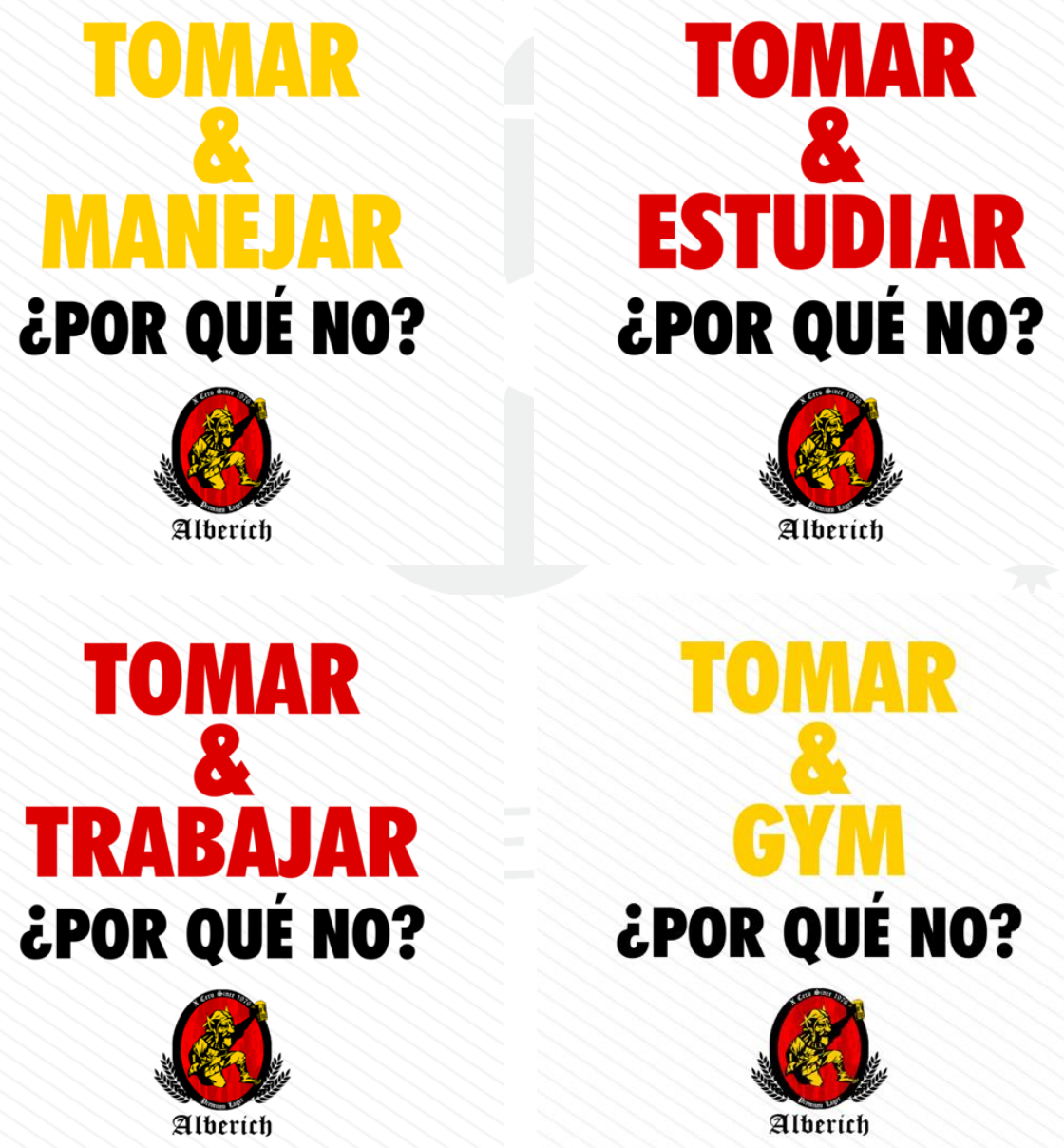

Fuente: Elaboración propia 
La razón por la que se ha elegido dichas plataformas es la siguiente. Facebook porque es la red social más utilizada por los peruanos y porque sirve de puente entre la comunidad y la página web de la marca. Instagram porque es una red social con bastante potencial en donde los jóvenes y adultos jóvenes están más dispuestos a recibir contenido publicitario que en otras plataformas, sobre todo si viene en formato multimedia. De ahí la importancia de trabajar con influencers. A continuación los personajes con los que trabajaría la marca.

TABLA 2. Influencers propuesto para campaña de intriga

\begin{tabular}{|l|l|c|}
\hline \multicolumn{1}{|c|}{ Influencer } & \multicolumn{1}{|c|}{ Temática de su canal } & Contenidos de marca \\
\hline Mateo Garrido Lecca & $\begin{array}{l}\text { Videos cómicos afines al } \\
\text { target masculino }\end{array}$ & $\begin{array}{l}\text { Lo que callan los } \\
\text { amigos elegidos. } \\
\end{array}$ \\
\hline Ximena Galiano & ¿Qué pasaría si...? \\
& target femenino & $\begin{array}{l}\text { Me tocó ser amiga } \\
\text { elegida } \\
\text { ¿Qué pasaría si...? }\end{array}$ \\
\hline
\end{tabular}

Fuente: Elaboración propia

Para la etapa de intriga se le asignará a cada influencer dos temas para que desarrollen y publiquen un video por semana, siendo dos en total. El primer tema corresponde al "amigo elegido", en donde los influencers representarán a manera de sketch lo que calla el "amigo elegido". Manuel hará un contenido más afín al público masculino, mientras que Ximena hará lo mismo para el público femenino. El cierre para ambos casos será "es momento de que tú también disfrutes la fiesta, Alberich... Disponible próximamente".

El segundo tema plantea qué pasaría si uno pudiese tomar cerveza sin sentir nada más que su rico sabor. En este caso tanto Manuel como Ximena desarrollarán las muchas cosas que podrían hacer, como tomar y manejar, tomar e ir al gym, tomar e ir a trabajar, etc. El cierre para este video será "tus sueños más cerca de volverse realidad. Alberich... Disponible 02/02/19”. Es importante añadir que a ambos personajes se les 
dará la libertad creativa de contar la historia que gusten, siempre y cuando se cumpla con la temática propuesta y se coloque el cierre mencionado.

\subsubsection{Campaña de lanzamiento}

Con el objetivo de generar conocimiento y recordación de marca entre el target, se dividirá la campaña de lanzamiento en tres etapas. La primera consistirá en sembrar interés en el tema, para ello se recurrirá a las relaciones públicas. La segunda tendrá como eje central el desarrollo de un contenido multimedia que narre la historia del duende Alberich y cómo es que decide ayudar a los humanos responsables que no pueden tomar alcohol. Finalmente se hará publicidad en redes sociales, prensa escrita, vallas publicitarias, televisión y cine. A continuación un cuadro resumen de lo mencionado.

TABLA 3. Cuadro resumen etapas de campaña lanzamiento

\begin{tabular}{|c|c|c|c|}
\hline $\begin{array}{l}\text { ETAPAS DE LA } \\
\text { CAMPAÑA DE } \\
\text { LANZAMIENTO }\end{array}$ & $\begin{array}{l}\text { HERRAMIENTAS } \\
\text { DE } \\
\text { COMUNICACIÓN }\end{array}$ & FUNCIÓN & ESTRATEGIAS \\
\hline $\begin{array}{l}\text { ETAPA UNO: } \\
\text { Sembrar interés en } \\
\text { el tema }\end{array}$ & Relaciones Públicas & $\begin{array}{l}\text { Comunicación de } \\
\text { marca: generar interés } \\
\text { en la gente sobre las } \\
\text { consecuencias de } \\
\text { manejar en estado de } \\
\text { ebriedad y la } \\
\text { importancia de cuidar } \\
\text { el consumo de alcohol } \\
\text { para la salud. }\end{array}$ & $\begin{array}{l}\text { Notas, reportajes, } \\
\text { noticieros, diarios, } \\
\text { etc. }\end{array}$ \\
\hline \multirow[t]{2}{*}{ 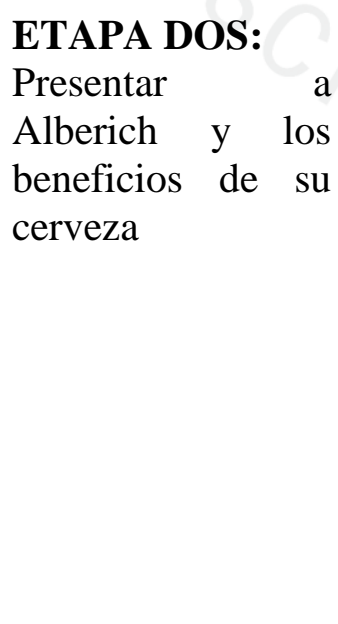 } & Video spot & $\begin{array}{l}\text { Presentar al duende } \\
\text { Alberich y contar su } \\
\text { historia. } \\
\text { Resaltar los } \\
\text { beneficios de la } \\
\text { cerveza sin alcohol. }\end{array}$ & $\begin{array}{l}\text { Videos cortos } \\
\text { colocados } \\
\text { estratégicamente } \\
\text { en Instagram y } \\
\text { Facebook. }\end{array}$ \\
\hline & $\begin{array}{l}\text { Buzz marketing / } \\
\text { BTL }\end{array}$ & $\begin{array}{l}\text { Convencer al público } \\
\text { sobre el buen sabor de } \\
\text { la cerveza }\end{array}$ & $\begin{array}{l}\text { Trabajo con } \\
\text { influencers } \\
\text { (embajadores de } \\
\text { marca) - videos } \\
\text { cortos }\end{array}$ \\
\hline
\end{tabular}




\begin{tabular}{|c|c|c|c|}
\hline & & & $\begin{array}{l}\text { romper el } \\
\text { prejuicio del mal } \\
\text { sabor. } \\
\text { Activación en un } \\
\text { evento musical. }\end{array}$ \\
\hline $\begin{array}{l}\text { ETAPA TRES: } \\
\text { Persuadir a los } \\
\text { jóvenes y adultos } \\
\text { jóvenes limeños } \\
\text { del NSE A y B a } \\
\text { probar la cerveza }\end{array}$ & Publicidad & $\begin{array}{l}\text { Comunicación masiva } \\
\text { que busca persuadir a } \\
\text { los consumidores a } \\
\text { probar la nueva } \\
\text { cerveza Alberich. }\end{array}$ & $\begin{array}{l}\text { Cine: Spot } \\
\text { TV: América } \\
\text { Paneles: } \\
\text { Led, } \\
\text { paradero } \\
\text { Digital: } \\
\text { Facebook, } \\
\text { Instagram } \\
\text { Prensa: } \\
\text { El } \\
\text { Comercio } \\
\text { Somos } \\
\text { Publimetro }\end{array}$ \\
\hline
\end{tabular}

Fuente: Elaboración propia

La etapa uno tendrá como escenario de acción los principales noticieros del Perú. Para nosotros es importante que se hable del tema y sobre la importancia de ser responsables. Los canales elegidos serán América Noticias y Noticias 90. Una vez culminada la etapa de relaciones públicas se desarrollará un contenido multimedia que presente al duende (personaje) Alberich junto a los beneficios de la cerveza. Este video será dividido en tres capítulos que se irán soltando en redes a medida que avance la campaña. A continuación el guión publicitario del video:

TABLA 4. Guión publicitario del video

\begin{tabular}{|l|l|l|}
\hline Video (Acciones) & $\begin{array}{l}\text { Audio (Diálogos, Voz en } \\
\text { Off, Etc.) }\end{array}$ & Tiempo \\
\hline PARTE UNO: & & \\
Se muestra un bar en una aldea de duendes. & (Suena música de entrada) & \\
$\begin{array}{l}\text { Un duende barbón yace sobre una mesa } \\
\text { alardeando su invicto de "más cervezas tomadas } \\
\text { sin causarle efecto". El resto de duendes lo mira } \\
\text { con admiración. }\end{array}$ & $\begin{array}{l}\text { (Suson chocánte festivo: } \\
\text { eufóricas, etc) }\end{array}$ & \\
\hline
\end{tabular}




\begin{tabular}{|c|c|c|}
\hline $\begin{array}{l}\text { Un duende desconocido entra por la puerta del } \\
\text { bar e interrumpe su discurso. } \\
\text { Todos voltean sorprendidos y empiezan a } \\
\text { calentar el ambiente ante una nueva } \\
\text { competencia. El duende barbón incluso se } \\
\text { sorprende pero en su afán de seguir } \\
\text { demostrándole a todos que es el mejor, acepta el } \\
\text { desafío. } \\
\text { Un duende mesero trae dos vasos de cerveza y } \\
\text { los pone sobre la barra. El duende barbón y } \\
\text { Alberich se acercan. Todo los duendes se ponen } \\
\text { alrededor. } \\
\text { Alberich mira el vaso y murmura algo. } \\
\text { Alberich y el duende barbón se dan la mano y } \\
\text { comienzan a tomar. } \\
\text { (Juego de cortes a medida que van avanzando) } \\
\text { Alberich se retira entre gritos desenfrenados } \\
\text { mientras un par de meseros tratan de levantar al } \\
\text { duende barbón. } \\
\text { toma más despacio. Alberich, por el contrario } \\
\text { sigue igual. En eso el duende barbón cae } \\
\text { desmayado sobre la mesa causando sorpresa y } \\
\text { emoción entre los presentes, nadie podía creer } \\
\text { que un desconocido había vencido al campeón } \\
\text { Alberich parece no tener problema con los vasos } \\
\text { mientras que el duende barbón sí. El resto de } \\
\text { duendes observa y alienta. } \\
\text { (Efecto paso de tiempo) } \\
\text { Pasan las horas y el duende barbón cada vez }\end{array}$ & $\begin{array}{l}\text { (Sonido vasos llenos } \\
\text { contra la mesa) } \\
\text { Duende mesero: Les } \\
\text { recuerdo las reglas, el } \\
\text { primero que deje de tomar } \\
\text { pierde.... } \\
\text { Duende mesero: Doy por } \\
\text { iniciada la competencia! } \\
\text { (Inicio música de } \\
\text { competencia) } \\
\text { (Sonido gritos de apoyo) } \\
\text { duende presente: Es } \\
\text { increíble, va a vencer al } \\
\text { campeón! }\end{array}$ & $\begin{array}{l}1: 20 \\
\min \\
\text { aprox }\end{array}$ \\
\hline
\end{tabular}




\section{PARTE DOS:}

Alberich camina entre el bosque y pasa por una fiesta a las afueras de la ciudad. Curioso por saber de qué trata, se acerca.

Un grupo de jóvenes está tomando en la terraza de una casa, algunos bailan y otros conversan. Uno esta sentado sin ningún vaso y con cara de aburrido. Alberich se sorprende y se acerca más. Se asoma por un arbusto.

Una pareja se acerca al chico que está aburrido.

Juan lo mira con resignación y responde.

La chica abraza a su pareja y trata de jalarlo para que no moleste a su amigo.

Juan se ríe incómodamente ante la situación.

Alberich queda confundido, no puede entender que alguien no se divierta en un fin de semana. Entonces decide ayudarlo.

Corte

Alberich va a su laboratorio y prepara una fórmula de lager con su truco de magia para que sepa buenaza y no tenga alcohol.

(Juego de cortes en el proceso de preparación)

1. Malteado: sumerge granos de cebada en agua.

2. Cocción: se hierve el mosto

3. Embotellado: en la botella Alberich Alcohol Free.

Alberich regresa con la botella dispuesto a 
ayudar a Juan. Se asoma por un arbusto y trata de pasarle la voz.

Juan no se da cuenta y sigue en lo suyo.

Alberich trata de cambiar la voz y la imposta como si fuese un joven millenial.

Juan, cansado de toda las veces que le han preguntado lo mismo, voltea a responderle.

Juan se sorprende por la apariencia extraña del duende

Alberich le responde rápido escondido desde un arbusto.

La chica regresa e interrumpe la conversación de Juan y Alberich.

Juan voltea a responderle.

Juan regresa con el duende pero ya no está. Juan confundido voltea a su mesa y ve la botella.

\section{PARTE 3}

Flashback:

Juan en su casa. Su madre le está dando las llaves del carro junto a un sermón de responsabilidad.

Juan, sentado en su sala, responde.

Juan regresa al presente y ve la cerveza en sus manos.

Mientras la examina recuerda las palabras del duende.
Alberich: Hey, humano, humano!

Alberich: Broder, una chelita?

Juan: No puedo, he venido....

Juan: ¿Qué eres?

Alberich: Necesitas una lager, prueba ésta, es buenaza y no tiene alcohol.

Amiga 1: ¿Juan con quién hablas?

Juan: Con nadie...

OFF locutor:

Continuará...

Madre: Juan Daniel, como me entere que has estado manejando y bebiendo me regresas las llaves del auto...

Juan: Sí mamá...

(Ambiente de fiesta, música electrónica a mucho volumen, risas, voces eufóricas)

OFF Alberich: es buenaza $\mathrm{y}$ no tiene alcohol.

Juan: No puede ser cierto... (murmurando) 
En eso aparece la chica que le gusta a juan.

Entrada en slow motion.

(Música de entrada)

Juan la mira idiotizado. Natalia se acerca y le habla.

Juan sigue en trance.

Juan sale del trance y ve la botella en su mano.

Para no quedar mal con ella le dice que si.

Juan abre la botella y toma un sorbo.

Juan al probar la cerveza se ve impresionado por el rico sabor, sus pupilas se dilatan y escucha un coro de ángeles.

Natalia se sienta a su costado y le pregunta si puede probar.

Juan, aún sorprendido, teme que descubra que no tiene alcohol, así que decide inventar algo... mira la etiqueta a ver que se le ocurre.

Natalia le responde rápido y le quita la botella para probar.

Natalia toma la cerveza mientras Juan cierra los ojos. En eso se da cuenta de algo...

Juan, desesperanzado, piensa que lo descubrió

Natalia le responde y sigue tomando.

Juan aliviado le sonríe, voltea hacia el arbusto y ve a Alberich haciéndole un guiño. Le sonríe y regresa con la chica.

Natalia: Juan? Estás bien? (efecto reverb)

Natalia: Estás tomando?

Juan: Claro, si yo siempre tomo...

(Coro de ángeles)

Natalia: Me invitas?

Juan: No creo que te guste, ehm... es alemana.

Natalia: Alemana? Estás bromeando, debe ser buenaza!

(Música de tensión)

Natalia: ¿Por qué no me dijiste?!

Juan: Natalia, puedo explicártelo!

Natalia: Es una lager, mi favorita!!

VOZ EN OFF: La magia está en el sabor, no en el alcohol. Alberich, nueva cerveza alemana sin alcohol. 
Como parte de la etapa dos también se trabajará con los influencers. En este caso se les pedirá que hagan un video en donde humorísticamente desarrollen el prejuicio del mal sabor en la cervezas sin alcohol y lo rico que sabe Alberich Alcohol Free. En este caso se les dará la libertad creativa de contar cómo la nueva cerveza sí tiene el verdadero sabor de una lager, a tal punto de no parecer sin alcohol. Además se informará sobre los puntos de venta del producto para que todos sepan dónde buscar la cerveza.

También se desarrollará una activación en un evento musical de la capital con el objetivo de "agarrar" al target en una situación desprevenida y poner a prueba el buen sabor de la cerveza. De este modo a mitad del concierto se les dirá que la única cerveza que se vendió esa noche no tenía alcohol, lo cual causará gracia y sorpresa entre los presentes. En ese momento se repartirán destapadores con el logo de Alberich para que el target se empiece a familiarizar con la marca a través de un merch útil y práctico.

GRÁFICA 7. Propuesta destapador Alberich

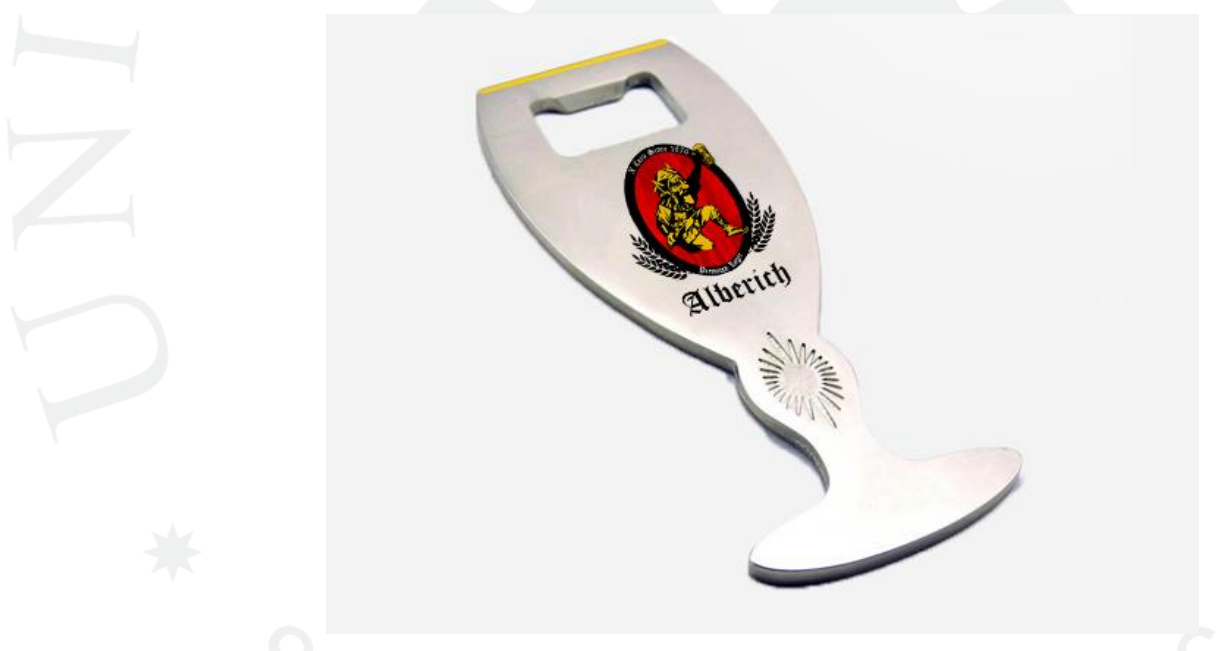

Fuente: Elaboración propia

La banda elegida para la activación será Laguna Pai y el local será una discoteca concurrida en Barranco. Laguna Pai es una banda reggae bastante querida por el segmento juvenil A y B, la cual además tiende a participar en proyectos que velan por el bienestar general de la ciudadanía. Ya lo han hecho en campañas de cuidado del agua, por lo que creemos que la seguridad vial podría serles de interés. La activación será registrada ese día y posteriormente compartida en las redes sociales de la marca.

Para la etapa tres se hará publicidad tanto en redes sociales como en prensa escrita, vallas publicitarias, televisión y cine. En estas comunicaciones se informará 
sobre los puntos de venta en donde estará disponible la cerveza. De este modo los consumidores podrán acercarse al lugar más cercano y así comprobar el rico sabor de la cerveza. El slogan que se utilizará en toda las piezas será "la magia está en el sabor, no en el alcohol”. A continuación el aviso base de prensa.

GRÁFICA 8. Propuesta aviso prensa

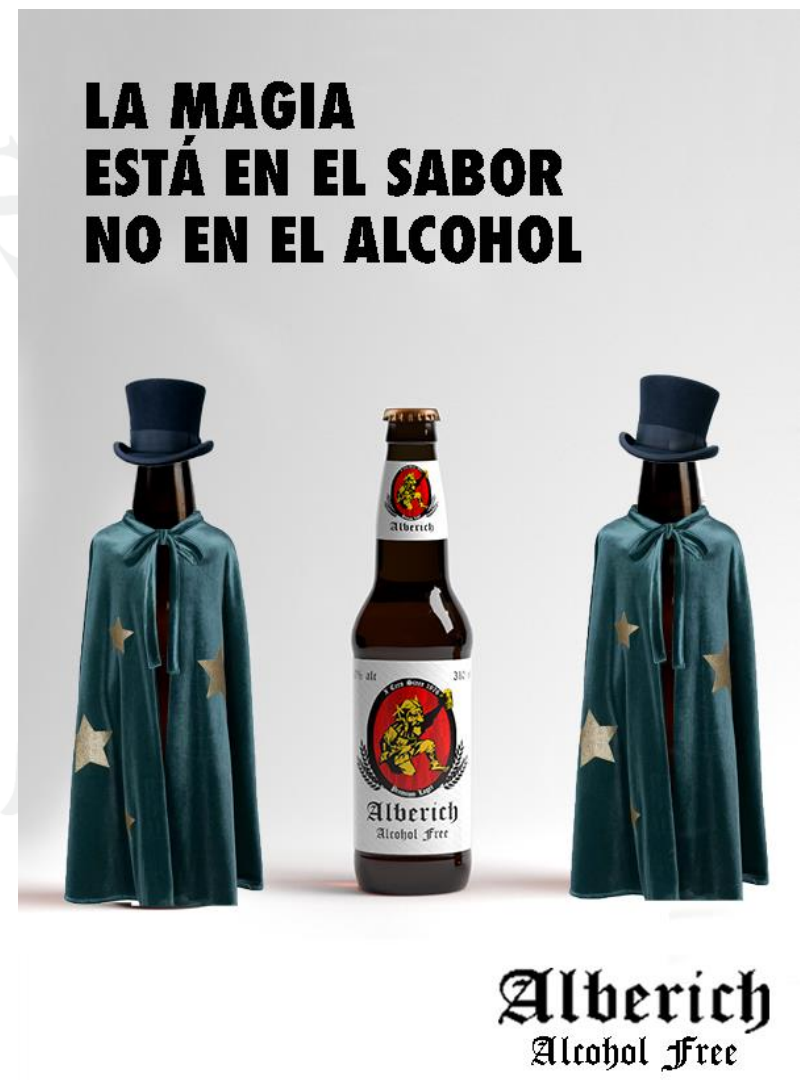

Fuente: Elaboración propia

Los diarios elegidos serán El Comercio, Somos y Publimetro. Para dichas comunicaciones se presentarán variaciones del aviso base de prensa con el objetivo de englobar y reforzar el concepto de magia y sabor propios de la marca.

Respecto a la publicidad en calles, esta se hará a través de paneles estáticos, paneles LED y paraderos afuera de las principales universidades de la capital y en los distritos de Miraflores, La Molina, San Borja, San Isidro y Surco, que son justo en donde vive, estudia o trabaja la mayor parte del target. El lapso de duración será de un mes. 
GRÁFICA 9. Paneles en las calles

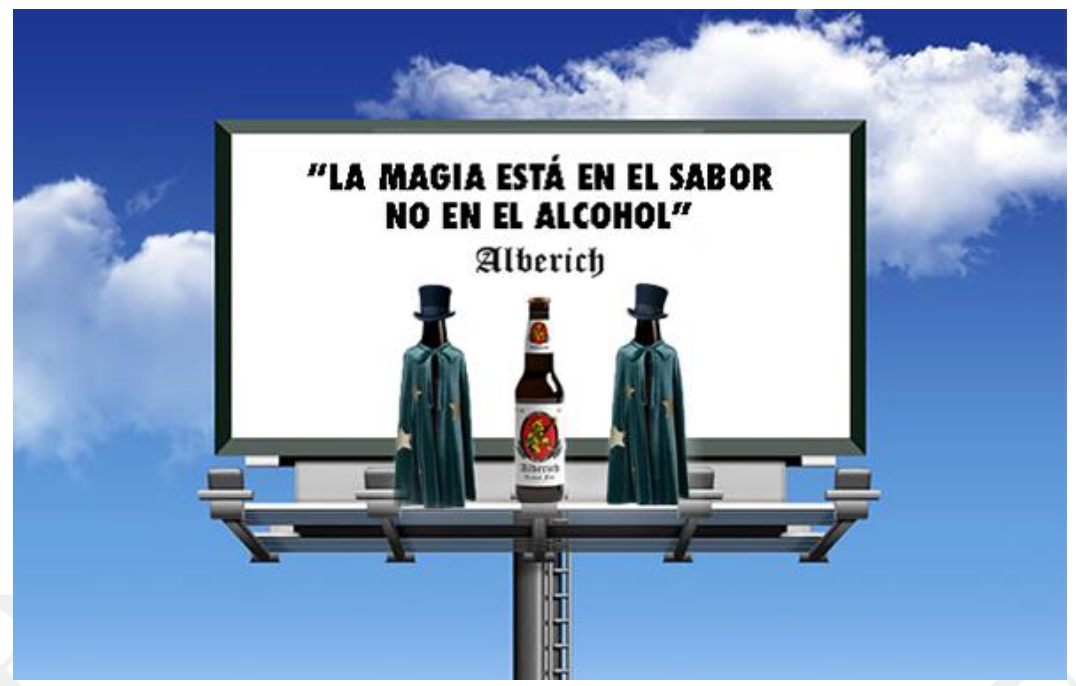

Fuente: Elaboración propia

GRÁFICA 10. Publicidad en paraderos

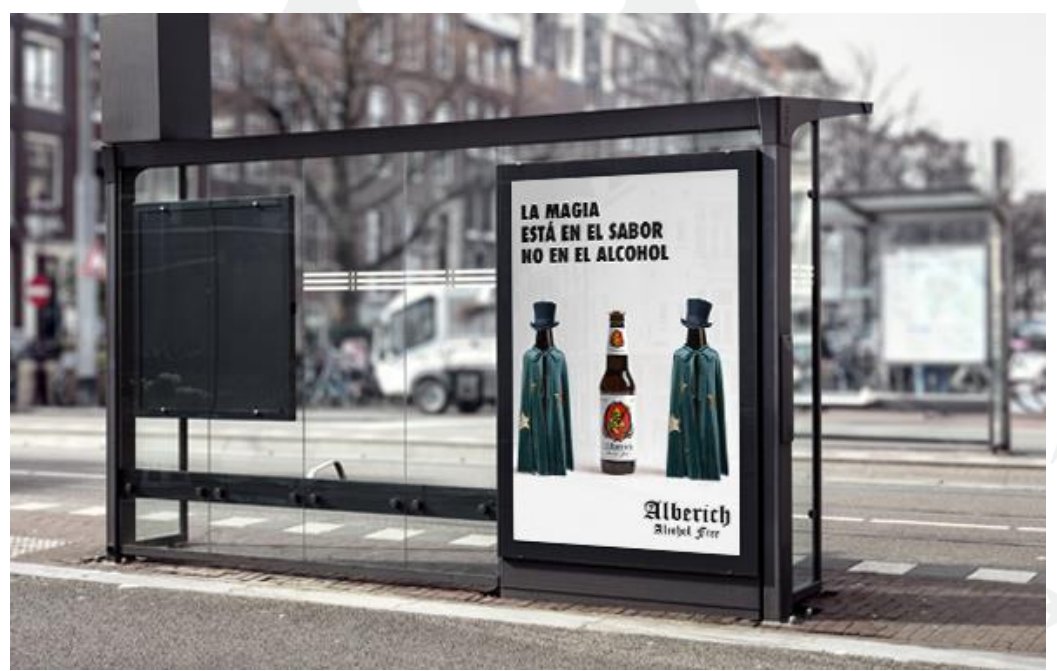

Fuente: Elaboración propia

Finalmente se hará una edición al video del duende Alberich para que sea proyectado en los principales cines de la capital y en el bloque estelar de América Televisión durante el lapso de un mes.

En el caso del cine, el video será proyectado en 6 salas súper Premium 30” en Alcazar, San Borja, Primavera, San Miguel, Salaverry y La Molina; y en 7 salas Premium 30" en el Centro Cívico, Sta. Clara, Guardia Civil, Brasil, Mall del Sur y Plaza Norte. Por otro lado, el comercial será transmitido en América TV en el horario de 8:30 a 9:30 pm, categoría AAA, de lunes a viernes. Este horario resulta atractivo ya 
que es el más visto por el target. La idea es reforzar el concepto del duende y que el consumidor genere un vínculo emocional con el personaje.

\subsubsection{Campaña de mantenimiento}

Para la campaña de mantenimiento se hará uso de Facebook, Instagram y la página web. Facebook servirá de puente entre el target y la página de Sonneco, en donde se encontrará la ventana "Alberich Alcohol Free". En ella los consumidores podrán saber más sobre la cerveza, su proceso de preparación, el por qué de su buen sabor, la historia del duende; además tendrá un portal en donde podrán participar subiendo sus anécdotas y las cosas que han podido hacer gracias a la nueva cerveza.

GRÁFICA 11. Pantalla de cómo se verá la página en Facebook

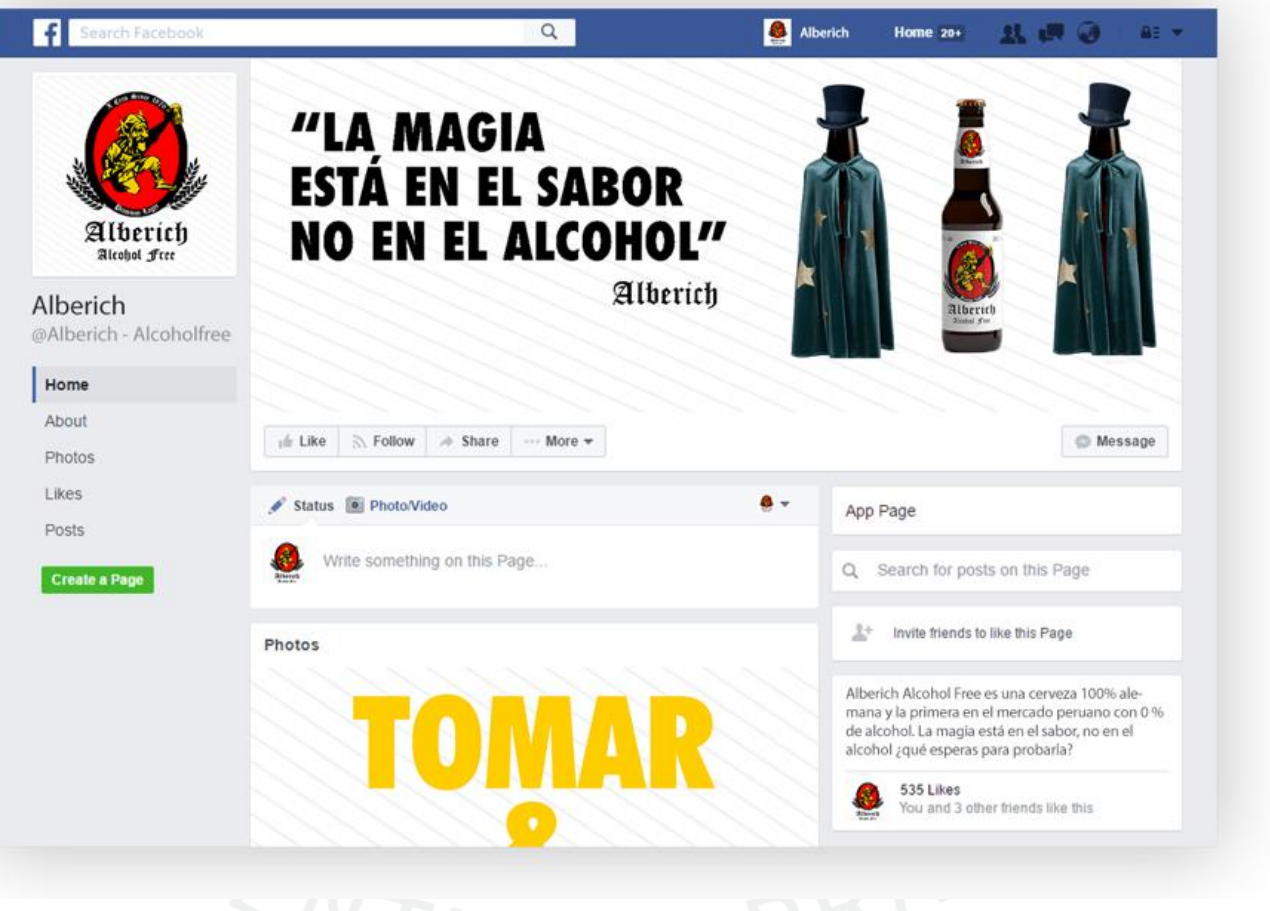

Fuente: Elaboración propia 
GRÁFICA 12. Pantalla de cómo se verá la página web

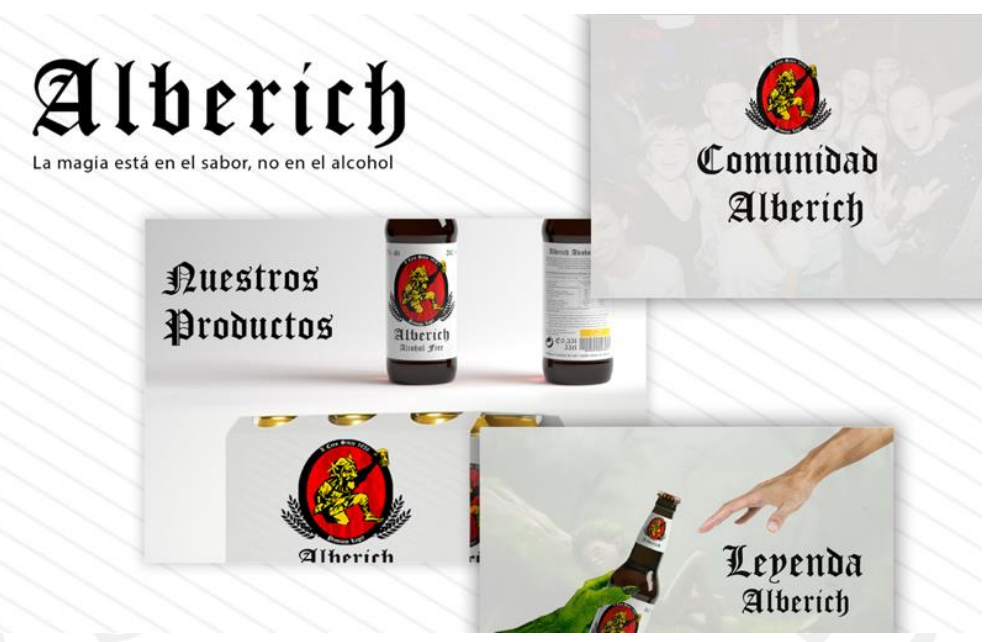

Fuente: Elaboración propia

\subsection{Cronograma}

\begin{tabular}{|c|c|c|c|c|c|c|}
\hline & \multicolumn{4}{|c|}{2019} & & \\
\hline \multirow[t]{2}{*}{ Tarea } & \multicolumn{5}{|c|}{ Mes } & \multirow{2}{*}{ Junio } \\
\hline & Enero & Febrero & Marzo & Abril & Mayo & \\
\hline $\begin{array}{l}\text { Video influencers } \\
\text { (3 por influencer)) }\end{array}$ & & & & & & \\
\hline Post intriga & & & & & & \\
\hline Relaciones públicas & & & & & & \\
\hline Post redes sociales & & & & & & \\
\hline Video Alberich & & & & & & \\
\hline Cine (spot) & & & & & & \\
\hline $\begin{array}{l}\text { Activación concierto } \\
\text { (Grabación y } \\
\text { lanzamiento) }\end{array}$ & & & & & & \\
\hline
\end{tabular}




\begin{tabular}{|l|l|l|l|l|l|l|}
\hline Paneles & & & & & & \\
\hline Prensa escrita & & & & & & \\
\hline TV & & & & & & \\
\hline $\begin{array}{l}\text { Contenido página } \\
\text { web }\end{array}$ & & & & & & \\
\hline
\end{tabular}

Duración en días:

\begin{tabular}{|l|l|l|l|l|}
\hline $\begin{array}{l}\text { Campaña } \\
\text { Intriga }\end{array}$ & $\begin{array}{l}\text { Campaña } \\
\text { lanzamiento }\end{array}$ & $\begin{array}{l}\text { Campaña } \\
\text { lanzamiento }\end{array}$ & $\begin{array}{l}\text { Campaña } \\
\text { lanzamiento }\end{array}$ & $\begin{array}{l}\text { Campaña } \\
\text { mantenimiento }\end{array}$ \\
\hline $\begin{array}{l}18 \text { enero a } 01 \\
\text { febrero }\end{array}$ & $\begin{array}{l}\text { febrero a 16 fe febrero a 20 } \\
\text { febrero }\end{array}$ & $\begin{array}{l}\text { 20 abril a } 18 \\
\text { mayo }\end{array}$ & $\begin{array}{l}18 \text { mayo a 29 } \\
\text { junio }\end{array}$ \\
\hline
\end{tabular}

\subsection{Presupuesto}

\begin{tabular}{|c|c|}
\hline \multicolumn{2}{|c|}{ RESUMEN GASTOS AGENCIA } \\
\hline ÍTEM & MONTO \\
\hline Personal & $\mathrm{S} / .44,040.00$ \\
\hline Trámites & $\mathrm{S} / .301,800.00$ \\
\hline Promoción & $\mathrm{S} / .20,300.00$ \\
\hline Diversos & $\mathrm{S} / .1,300.00$ \\
\hline Servicios & $\mathrm{S} / .620 .00$ \\
\hline Impresiones & $\mathrm{S} / .509,010.91$ \\
\hline TV & $\mathrm{S} / .3,332.00$ \\
\hline Alimentación & $\mathrm{S} / .889,984.91$ \\
\hline SUBTOTAL & $\mathrm{S} / .88,998.49$ \\
\hline 10\% & $\mathrm{S} / .978,989.40$ \\
\hline TOTAL &
\end{tabular}

Monto en dólares: 295,265.83* Ver detalle en Excel adjunto. 


\section{REFERENCIAS}

Backus. (07 de Setiembre de 2018). Backus.pe. Recuperado el 07 de setiembre de 2018, de Backus: http://backus.pe

Viuda, J. d. (09 de Mayo de 2018). Cámara Lima. Recuperado el 08 de Setiembre de 2018, de Cámara Lima: el consumo per cápita [de bebidas alcohólicas] es de 22 tragos al mes, cifra inferior a la de México (30), Chile (37) Argentina (42) y EE.UU. (49)

Economista, E. (09 de Mayo de 2018). El Economista. Recuperado el 05 de Setiembre de 2018, de El Economista: http://www.eleconomistaamerica.pe/mercadoseAm-peru/noticias/9127353/05/18/Sector-licores-creceria-10-en-el-2018.html

EC, R. (08 de Mayo de 2017). El Comercio. Recuperado el 09 de Setiembre de 2018, de El Comercio: https://elcomercio.pe/economia/backus-marcas-domina-mercadocervecero-peru-fotos-noticia-447675

Matos, C. (19 de Febrero de 2014). Perú 21. Recuperado el 11 de Setiembre de 2018, de Perú 21: https://peru21.pe/opinion/peru-buena-cerveza-145564

Eyzaguirre, J. L. (28 de Agosto de 2017). El Comercio. Recuperado el 10 de Setiembre de 2018, de El Comercio: https://elcomercio.pe/economia/dia-1/corona-caballobatalla-superpremium-noticia-453632

Gourmetógrafo, E. (12 de Setiembre de 2016). Tomandoaltura. Recuperado el 11 de Setiembre de 2018, de Tomandoaltura: http://tomandoaltura.com/cerveza-sinalcohol/beers/

Euromonitor. (13 de Setiembre de 2016). Euromonitor. Recuperado el 11 de Setiembre de 2018, de Euromonitor: https://www.euromonitor.com/beer-in-peru/report

Schneider, A. (05 de Octubre de 2017). Infoturperú. Recuperado el 04 de Setiembre de 2018 de

Infoturperú: 
https://www.infoturperu.com.pe/index.php/entrevistas/item/2079-crecimientoexponencial-experimenta-la-cerveza-artesanal-en-el-peru

Parra, S. (14 de Junio de 2016). Yorokobu. Recuperado el 11 de Setiembre de 2018, de Yorokobu: https://www.yorokobu.es/la-aceptacion-social/

CONCORTV. (2018). Estudio cuantitativo sobre consumo radial y televisivo nacional. Lima: CONCORTV.

CPI. (2017). Perú: Población 2017. Lima, Perú: CPI.

RAE. (13 de Setiembre de 2018). RAE. Recuperado el 11 de Setiembre de 2018, de RAE: http://dle.rae.es/srv/search?m=30\&w=soberano

BBC. (23 de Abril de 2016). BBC. Recuperado el 13 de Setiembre de 2018, de BBC: https://www.bbc.com/mundo/noticias/2016/04/160423_cultura_alemania_por_q ue_cerveza_buena_ley_pureza_500_anos_ppb

IPSOS. (2017). Medios tradicionales: Hábitos y actitudes. Lima: IPSOS.

Berghoff Beer. (14 de Agosto de 2013). Berghoff. Recuperado el 12 de Setiembre de 2018, de Berghoffbeer: http://berghoffbeer.com/blog/what-does-the-color-ofyour-beer-bottle-mean/

IPSOS. (2018). Perfil del usuario en redes sociales. Lima: IPSOS.

IPSOS. (2018). Perfil del adulto joven peruano. Lima: IPSOS.

Garboza, A. (09 de Mayo de 2018). Código. Recuperado el 11 de Setiembre de 2018, de Código: https://codigo.pe/brian-perkins-budweiser-peru-rusia-2018/

Don Juerguero. (30 de Setiembre de 2017). El Bunker. Recuperado el 08 de Setiembre de 2018, de El Bunker: http://elbunker.pe/las-cervezas-mas-populares-del-peru/ 